\title{
Single-Cell Stimulation in Barrel Cortex Influences Psychophysical Detection Performance
}

\author{
(DNouk Tanke, J. Gerard G. Borst, and Arthur R. Houweling \\ Department of Neuroscience, Erasmus MC, University Medical Center, 3015 GE Rotterdam, The Netherlands
}

\begin{abstract}
A single whisker stimulus elicits action potentials in a sparse subset of neurons in somatosensory cortex. The precise contribution of these neurons to the animal's perception of a whisker stimulus is unknown. Here we show that single-cell stimulation in rat barrel cortex of both sexes influences the psychophysical detection of a near-threshold whisker stimulus in a cell type-dependent manner, without affecting false alarm rate. Counterintuitively, stimulation of single fast-spiking putative inhibitory neurons increased detection performance. Single-cell stimulation of putative excitatory neurons failed to change detection performance, except for a small subset of deep-layer neurons that were highly sensitive to whisker stimulation and that had an unexpectedly strong impact on detection performance. These findings indicate that the perceptual impact of excitatory barrel cortical neurons relates to their firing response to whisker stimulation and that strong activity in a single highly sensitive neuron in barrel cortex can already enhance sensory detection. Our data suggest that sensory detection is based on a decoding mechanism that lends a disproportionally large weight to interneurons and to deep-layer neurons showing a strong response to sensory stimulation.
\end{abstract}

Key words: decision; interneuron; layer V; rat; sensory detection; whisker

\section{Significance Statement}

Rat whisker somatosensory cortex contains a variety of neuronal cell types with distinct anatomical and physiological characteristics. How each of these different cell types contribute to the animal's perception of whisker stimuli is unknown. We explored this question by using a powerful electrophysiological stimulation technique that allowed us to target and stimulate single neurons with different sensory response types in whisker cortex. In awake, behaving animals, trained to detect whisker stimulation, only costimulation of single fast-spiking inhibitory neurons or single deep-layer excitatory neurons with strong responses to whisker stimulation enhanced detection performance. Our data demonstrate that single cortical neurons can have measurable impact on the detection of sensory stimuli and suggest a decoding mechanism based on select cell types.

\section{Introduction}

Detection of sensory stimuli is a fundamental function of the brain, but how neuronal population activity patterns encode sensory information is still incompletely understood (Gold and Shadlen, 2007; Romo et al., 2012). The standard neural decisionmaking model, based on signal detection theory, holds that sensory evidence in the form of neuronal spikes is integrated across

\footnotetext{
Received July 31, 2017; revised Dec. 20, 2017; accepted Jan. 9, 2018.

Author contributions: N.T., J.G.G.B., and A.R.H. designed research; N.T. performed research; N.T. and A.R.H. analyzed data; N.T., J.G.G.B., and A.R.H. wrote the paper.

This work was supported by Netherlands Organisation for Scientific Research Grant Vidi 864.08 .006 (A.R.H.). We thank M. Stüttgen and P. Tiesinga for discussions and comments on an earlier version of this manuscript.

The authors declare no competing financial interests.

Correspondence should be addressed to J. Gerard G. Borst, Department of Neuroscience, Ee1202b, Erasmus MC, University Medical Center, P.0. Box 2040, 3000 CA, Rotterdam, The Netherlands. E-mail: g.borst@erasmusmc.nl.

N. Tanke's present address: Centre for Neural Computation, Kavli Institute for Systems Neuroscience, Norwegian University of Science and Technology, Olav Kyrres Gate 9, 7030 Trondheim, Norway.

DOI:10.1523/JNEUROSCI.2155-17.2018

Copyright $\odot 2018$ the authors $\quad 0270-6474 / 18 / 382057-12 \$ 15.00 / 0$
}

sensory neurons, and that a behavioral response is generated after crossing a threshold (Gold and Shadlen, 2007; Brody and Hanks, 2016). This model has received support from experiments in both monkeys and rodents (Cook and Maunsell, 2002; Stüttgen and Schwarz, 2010). Theoretical work has demonstrated that the optimal (linear) readout of neuronal decision pools consists of weighting the spike counts of individual neurons such that weights reflect the sensitivity of neurons to sensory stimulation (Jazayeri and Movshon, 2006; Haefner et al., 2013). With regard to the size, identity, and readout of the decision pool, two types of experimental approaches have been informative.

First, the spike discharges of cortical sensory neurons believed to contribute to perceptual decisions often display weak correlations with behavioral choice, which are typically quantified as "choice probability" (Britten et al., 1996). In agreement with the optimal decoding scheme, choice probabilities are often highest in the neurons that are most sensitive for a given psychophysical task (Britten et al., 1996; Cook and Maunsell, 2002; Purushothaman and Bradley, 2005; Bosking and Maunsell, 2011; Yang et al., 
2016). However, the impact of individual neurons on perceptual detection cannot be inferred from choice probability alone, as choice probability may also arise from noise correlations, which is the degree to which response variability is shared with other sensory neurons (Shadlen et al., 1996; Nienborg et al., 2012; Haefner et al., 2013; Kohn et al., 2016). A significant choice probability therefore does not necessarily indicate involvement of the sensory neuron in the decision process, and the interpretation of choice probability is further complicated by feedback and feedforward signals to primary sensory areas from other cortical areas.

In the second type of experiments, optical or electrical stimulation is used to manipulate the firing of sensory cortical neurons during a detection or discrimination task (Salzman et al., 1992; Afraz et al., 2006; H. Kim et al., 2016; Sachidhanandam et al., 2016), thus establishing a causal link between neuronal firing and sensory perception. Photostimulation of brief trains of action potentials (APs) in about 60 pyramidal neurons in layer $2 / 3$ of the barrel cortex could be reliably detected by mice trained to report photostimulation (Huber et al., 2008). Nanostimulation experiments provided evidence that bursts of activity of even a single neuron can lead to behavioral responses in rats trained to report microstimulation (Houweling and Brecht, 2008; Doron et al., 2014). Several microstimulation studies showed that the size of the stimulation-induced perceptual bias in a discrimination task depends on the sensory tuning properties of neurons near the stimulation site (Romo et al., 2000; Nichols and Newsome, 2002; Ditterich et al., 2003), suggesting that neurons with different tuning properties are unequally weighted in perceptual decisions. However, a limitation of these types of microstimulation and photostimulation experiments is that the natural firing pattern of neurons is replaced by a hypersynchronous activation of an ensemble of neurons that is grouped together as a result of physical proximity to the electrode (or the light source) rather than by functional connectivity (Stanley, 2013). Since even nearby sensory cortical neurons may vary widely in their tuning properties, the interpretation of these stimulation experiments is not altogether straightforward, and they do not allow a measurement of the contribution of individual stimulated neurons.

To overcome some of these limitations, we therefore employ juxtacellular single-neuron nanostimulation (Houweling et al., 2010; Stüttgen et al., 2017) in rat barrel cortex to assess the readout weights of neurons involved in a whisker stimulation detection task (Stüttgen and Schwarz, 2008). Neuronal activity in barrel cortex is both necessary and sufficient for the detection of passively applied single whisker deflections (Miyashita and Feldman, 2013; Sachidhanandam et al., 2013).

We show that single-cell stimulation (eliciting approximately seven APs in $200 \mathrm{~ms}$ ) enhanced detection of a whisker stimulus, but only when we stimulated fast-spiking (FS) putative interneurons or cortical neurons that were highly sensitive to whisker deflections. These results suggest that sensory detection is based on a decoding mechanism that lends a disproportionally large weight to interneurons and neurons showing a strong response to whisker stimulation.

\section{Materials and Methods}

Animals and surgery. All experiments were conducted in accordance with Dutch guidelines on animal welfare and approved by the Erasmus MC, University Medical Center animal ethics committee. We used standard surgical techniques to prepare Wistar rats for chronic head-restrained electrophysiological recording of the barrel cortex (Houweling and Brecht, 2008). Animals were implanted under ketamine/xylazine (100 $\mathrm{mg} \cdot \mathrm{kg}^{-1}$ and $5 \mathrm{mg} \cdot \mathrm{kg}^{-1}$, respectively) anesthesia (intraperitoneal injections, supplementary injections administered as needed) or isoflurane anesthesia, with a metal bolt for head fixation and a recording chamber ( $2.5 \mathrm{~mm}$ posterior, $5.5 \mathrm{~mm}$ lateral from bregma) for chronic access to barrel cortex. Animals were individually housed and maintained on a $12 \mathrm{~h}$ light/dark cycle. Experiments were performed during the light phase.

Behavioral procedures. Animals were habituated to head fixation for several days after the surgery and trained to lick water containing artificial sweetener ( $97 \%$ maltodextrin, $3 \%$ aspartame, $0.01 \mathrm{~g} \mathrm{ml}^{-1}$ ) from a spout (Fig. 1A). During training, animals were kept on a water restriction schedule with ad libitum access to water for $1 \mathrm{~h}$ per day. Animals were subsequently trained to report a small, constant amplitude, backward movement applied to a single whisker (Stüttgen and Schwarz, 2008). The $\mathrm{C} 1$ whisker was inserted in a thin tube inside a glass capillary attached to a piezo bender. The tube was placed $\sim 5 \mathrm{~mm}$ from the whisker base at $35^{\circ}$ relative to the basal position of the whisker. Initially, animals were presented with high-velocity stimuli (duration, $4 \mathrm{~ms}$; peak velocity, $4528^{\circ} \cdot \mathrm{s}^{-1}$ ) delivered at random intervals. Stimuli were composed of a fast half cosine wave followed by a 500 ms plateau and a slow $(1 \mathrm{~s})$ half cosine wave (Fig. 2). The amplitude of movement was $1.02 \mathrm{~mm}$, which corresponds to $11.5^{\circ}$ when applied $5 \mathrm{~mm}$ from the whisker base. Animals received a water reward $(\sim 9 \mu \mathrm{l})$ for licking within a response window of $100-600 \mathrm{~ms}$ after stimulus onset. To discourage guessing, animals were 
Reward window $500 \mathrm{~ms}$

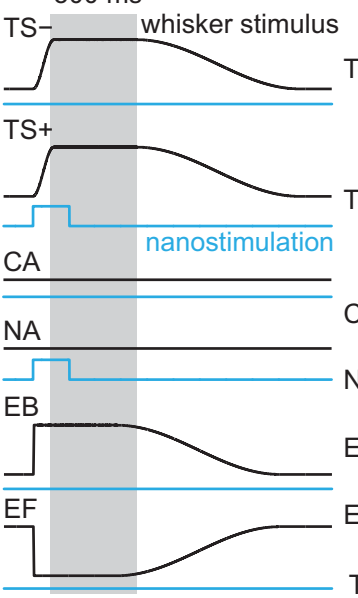

Trials

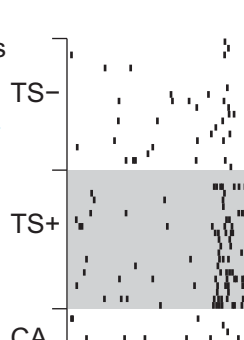

Reward window

Response rate

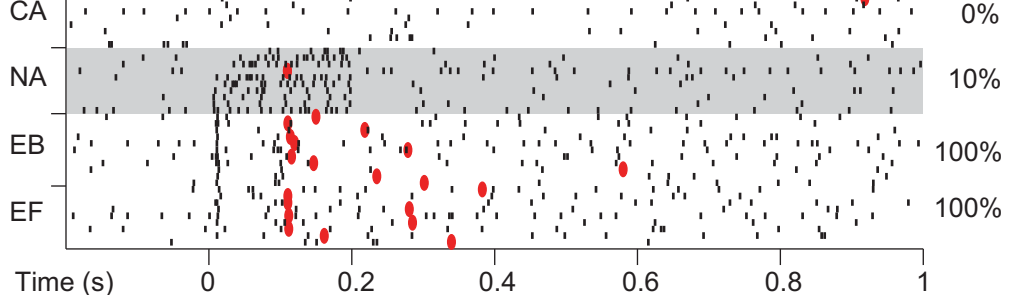

Figure 2. Example nanostimulation experiment. Left, Six types of trials were presented during single-cell-stimulation experiments. Licks were rewarded within the $100-600 \mathrm{~ms}$ window after stimulus onset (gray box) for all six trial types (black, whisker movement; blue, nanostimulation). The time of the first lick was taken as the reaction time. Right, Behavioral and neuronal responses in a nanostimulation experiment on a putative excitatory neuron (out of a population of 167 cells). The cell was recorded at a depth of $892 \mu \mathrm{m}$ and fired action potentials in response to stimulation of the $\mathrm{C} 1$ whisker. The raster plot depicts action potentials (ticks) and first lick responses (red filled circles) during the six different trial types. Stimulus onset is at time 0 . Behavioral responses are quantified on the right as a percentage of the total number of trials for each trial type.

given a brief time-out $(1.5 \mathrm{~s})$ when they licked outside the response window. In subsequent training sessions, the velocity of the whisker stimulus was lowered according to a staircase procedure targeting a $60 \%$ hit rate. After several training sessions, animals had reached asymptotic performance (Fig. 1B), and we characterized psychophysical performance using the method of constant stimuli (Fig. 1C), during which whisker stimuli were presented at eight different velocities in a pseudorandom sequence. The whisker stimulus yielding a response rate closest to $50 \%$ was subsequently used as threshold whisker stimulus in singlecell-stimulation experiments (median duration, $128 \mathrm{~ms}$; peak velocity, $141^{\circ} \cdot \mathrm{s}^{-1}$ ). The threshold value was reconfirmed at the onset of each single-cell-stimulation session and adjusted between experimental sessions when necessary.

Electrophysiological recording sessions lasted a maximum of $3 \mathrm{~h}$. At the onset of single-cell-stimulation experiments, rats were provided with a few free rewards to indicate the start of the experiment. During singlecell-stimulation experiments, trials were presented in pseudorandom order using blocks of eight stimuli. Each block contained two threshold whisker stimulation trials without concurrent nanostimulation (TS-) and two with concurrent nanostimulation (TS + ), one catch trial without any form of stimulation (CA), one nanostimulation alone trial without concurrent whisker stimulation (NA), and two easily detectable highvelocity $\left(4528^{\circ} \cdot \mathrm{s}^{-1}\right)$ whisker stimulation trials, one in the backward direction (EB) and one in the forward direction (EF; Fig. 2). Trials were separated by a uniform random time interval of $4 \pm 1.25 \mathrm{~s}$. Licks outside the response window added a $1.5 \mathrm{~s}$ time-out. Single-cell-stimulation experiments lasted on average $9.7 \mathrm{~min}$ (range, 3.8-22.4 min) and included an average number of 96 trials per experiment (range, 40-220 trials; aborted trials excluded).

Electrophysiology. Locations of the $\mathrm{C} 1$ and surrounding barrel columns were mapped using tungsten microelectrode recordings at a depth of $600-900 \mu \mathrm{m}$. Juxtacellular recordings were subsequently targeted to the C1 barrel column during single-cell-stimulation experiments. However, in three animals, the $\mathrm{C} 1$ barrel column was located outside the exposure, and recordings were targeted to a neighboring barrel column $(\gamma$, two animals, $n=16$ cells; D1, one animal, $n=8$ cells), and the corresponding whisker was stimulated. In two animals ( $n=12$ cells) the D1 whisker and corresponding barrel column were used for additional experiments after initial experiments on the $\mathrm{C} 1$ whisker/ barrel column. Although animals had been trained to stimulation of the $\mathrm{C} 1$ whisker, they responded equally well to stimulation of adjacent whiskers.
Glass pipettes (tip resistance, 3.5-6.5 $\mathrm{M} \Omega$ ) used for juxtacellular recordings and nanostimulation were filled with Ringer solution containing the following (in $\mathrm{mm}$ ): $135 \mathrm{NaCl}, 5.4 \mathrm{KCl}, 5 \mathrm{HEPES}, 1.8 \mathrm{CaCl}_{2}$, and 1 $\mathrm{MgCl}_{2}, \mathrm{pH}$ 7.2. Recordings were targeted through the intact dura to the barrel column corresponding to the stimulated whisker and were performed across all layers (range of depth meter readings, 300-1800 $\mu \mathrm{m}$ ). The exposure was covered with agarose ( $2 \% \mathrm{w} / \mathrm{v}$ in Ringer) to improve the stability of recordings. Neurons were approached by monitoring pipette resistance, and juxtacellular nanostimulation $(200 \mathrm{~ms}$ DC current injections) was applied when spikes had a minimum size of $2 \mathrm{mV}$ (Houweling et al., 2010; Figure 1D). Nanostimulation current $(4.8 \pm 2.8 \mathrm{nA}$, mean $\pm \mathrm{SD}$ ) was adjusted until the neuron fired $\sim 5-15$ APs during current injections. Data were obtained using Spike2.

Experimental design and statistical analysis. The (pseudo)randomized block design to test the impact of nanostimulation on perception is described above in Behavioral procedures. We analyzed a total of 167 neurons from 26 rats ( 25 males, 1 female; postnatal day 29-65 at the day of surgery) that were successfully stimulated during juxtacellular recording and for which at least 5 CA, 5 NA, 10 TS-, and 10 TS+ trials were collected that satisfied our inclusion criterion. We restricted the analysis of behavioral responses to those TS+, TS-, NA, and CA trials in which animals were considered attentive, as judged by their performance in reference trials (Houweling and Brecht, 2008; Doron et al., 2014). Specifically, for each neuron, we included only trials in which the animal responded to both the preceding and the succeeding reference (EB/EF) stimuli and excluded aborted trials, in which animals responded within $100 \mathrm{~ms}$ after trial onset. This resulted in an average number of $21.7 \mathrm{TS}-$, 21.8 TS+, 10.9 CA, 10.7 NA, 11.7 EB, and 11.7 EF trials per cell. On average, 6.7 single-cell-stimulation experiments were included per animal (range, 1-12).

Additionally, 13 neurons were successfully stimulated in line with the criteria above, but they were excluded from the data set because the animal deployed a continuous licking strategy leading to a mean response rate in CA and NA trials larger than 50\%. Most of these cells ( 12 of 13) were recorded in two rats. The mean response rates for CA $(72.1 \%)$ and NA $(76.5 \%)$ trials were similar in these excluded sessions $\left(t_{(12)}=\right.$ $1.01, p=0.33$, paired $t$ test).

Nanostimulation-induced APs are reported as the mean number of APs during the $200 \mathrm{~ms}$ current injections in NA trials minus the mean number of APs in the $200 \mathrm{~ms}$ prestimulus window, because NA trials were not contaminated with whisker-movement-induced spikes. 
Spike train irregularity was quantified as the coefficient of variation of the interspike intervals $\left(\mathrm{CV}_{\text {ISI }}\right)$ during nanostimulation, which was calculated for cells that had five or more NA trials with at least four APs per trial.

Groupwise differences between the numbers of spikes triggered during hit and miss trials in a $100 \mathrm{~ms}$ window following the onset of TS stimuli were assessed separately for TS - and TS + trials using paired $t$ tests. One FS cell that lacked hit trials for TS - stimuli was excluded from the TShit/miss analysis; all other FS and high-sensitivity (HS) cells had a minimum of four hit trials and four miss trials.

The response to whisker stimulation for a given neuron was analyzed by constructing a temporal response profile based on the spike counts in a sliding $25 \mathrm{~ms}$ window summed over all EB trials. We bootstrapped the prestimulus $(2 \mathrm{~s})$ recordings to determine a baseline distribution of spike counts and calculate a sensitivity index [area under the receiver operating characteristic curve (auROC)] for all time bins, yielding the neuronal response profile (Cohen et al., 2012). We then applied principal component analysis (PCA) to the $0-100 \mathrm{~ms}$ poststimulus response profiles and used $k$ means clustering to classify the first three principal component scores into four clusters. The clustering procedure was repeated with 1000 different initial conditions to obtain a final solution with the lowest total sum of distances over all replicates. The HS neurons formed a strong cluster (with cluster strength $D=3.2$; Fellous et al., 2004), which was consistently obtained when the number of clusters was varied $(k=2-7)$. The $k$ means resulted in better clustering performance than two other commonly used clustering algorithms applied to spike data, fuzzy $c$ means clustering (Fellous et al., 2004) and hierarchical clustering (Cohen et al., 2012), according to several clustering indices. The cluster of HS neurons was identical across all clustering methods, whereas the other clusters could slightly vary in composition.

The effect of single-cell stimulation on behavioral responses was evaluated using a two-sided paired $t$ test, as in previous studies (Houweling and Brecht, 2008; Doron et al., 2014). In addition, we computed bootstrapped $95 \%$ confidence intervals (CIs) to confirm all test results. Comparisons between clusters were performed using a Kruskal-Wallis test. Variances were similar between clusters for all comparisons (Levene's test for equal variances across multiple groups). Two-sided $p$ values for Pearson's correlation coefficient $r$ were computed using a Student's $t$ distribution. The Holm-Bonferroni method was used where indicated to control for the familywise error rate with $m$ multiple comparisons ( $\alpha=$ 0.05). All statistical tests were performed in MATLAB.

Detection model. We constructed a simple threshold detection model (Cook and Maunsell, 2002; Stüttgen and Schwarz, 2010) based on our electrophysiological recordings of HS cells during behavioral experiments and investigated how the sensory detection increase induced by single-cell stimulation depended on the number of neurons included in the decision pool. To simulate a behavioral trial ( of the EB, TS - , TS +, or CA type), each model neuron was paired with an HS cell recorded during behavioral experiments and a spike discharge was sampled at random (with replacement) from the corresponding set of trials in the HS cell. All HS cells contributed equally to the pool. Single-cell stimulation was applied to one of the model neurons by sampling spike discharges from the set of TS + trials of its corresponding HS cell. The spike discharges of pool neurons were then summed and convolved with an exponential filter $(\tau=50 \mathrm{~ms})$ to construct a population signal. The model based its decision to generate a behavioral response on simple threshold crossings of the population signal in a -100 to $400 \mathrm{~ms}$ time window with respect to stimulus onset (such that the motor response would fall in the 100$600 \mathrm{~ms}$ poststimulus reward window assuming a motor preparation/ execution time of $200 \mathrm{~ms}$ ). The response criterion was set to obtain a behavioral response in $50 \%$ of threshold whisker stimulation (TS-) trials (see Fig. 8A). To estimate the pool size for which the sensory detection change (i.e., the difference in response rates between TS + and TStrials) induced by single-HS-cell stimulation matched the experimentally observed value, we simulated a set of six single-cell-stimulation experiments (one per HS cell). Each experiment included $25 \mathrm{~EB}, 25 \mathrm{TS}+, 25$ TS - , and 25 CA trials. The sensory detection change induced by singleHS-cell stimulation was calculated for each experiment and averaged over the set of six experiments to obtain a mean sensory detection change. Each set of six experiments was then repeated 400 times for a given pool size to assess the variability of the mean sensory detection change (see Fig. $8 B$ ). Very similar results were obtained in models with different exponential integration windows $(\tau=25 / 100 \mathrm{~ms})$ and in a slightly different version of the model in which random spike trains were generated for each model neuron based on measured spike probabilities across time (Stüttgen and Schwarz, 2010). MATLAB code describing the detection model will be provided upon request.

\section{Results}

Animals were trained to report a low-amplitude $\left(11.5^{\circ}\right)$ backward movement applied to the $\mathrm{C} 1$ whisker at random intervals (Fig. 1A). They received a water reward for lick responses within a response window of 100-600 ms following stimulus onset. Training started with high-velocity whisker stimuli, but animals gradually responded to lower-velocity stimuli during the following daily sessions (Fig. 1B). When psychophysical performance no longer improved (typically after three or four sessions), we determined for each animal a stimulus velocity that yielded a response rate close to $50 \%$ (Fig. 1C) and called the corresponding stimulus the threshold stimulus (TS). We next asked whether inducing a train of APs in a single barrel cortical neuron coapplied with the TS could change the animal's response to whisker stimulation. To induce APs in single cortical neurons, we applied nanostimulation (Houweling et al., 2010; Stüttgen et al., 2017), a technique that allows manipulation of single neuron activity by juxtacellular current injection (Fig. 1D).

Animals were presented with six different types of trials (Fig. 2, left): TS alone (TS-), TS with concurrent nanostimulation $(\mathrm{TS}+)$, easily detectable high-velocity $\left(4528^{\circ} \cdot \mathrm{s}^{-1}\right)$ whisker stimulation in the backward direction (EB) or the forward direction (EF), nanostimulation alone without whisker stimulation (NA), and catch trials without any form of stimulation (CA). The six types of trials were presented in pseudorandom order at random intervals. The high-velocity whisker stimuli evoked reliable, welltimed behavioral responses (Fig. $3 B, C$ ) and were included to keep animals motivated, as well as to assess receptive field properties of the stimulated neuron. The right panel in Figure 2 shows an example of a nanostimulation experiment targeted to a single neuron in the $\mathrm{C} 1$ barrel column. The cell increased AP firing in response to high-velocity deflections of the $\mathrm{C} 1$ whisker (EB and EF trials) and also, but to a lesser extent, in response to threshold velocity (TS-) whisker deflections. As expected, the animal responded in all 20 high-velocity (EB or EF) whisker stimulation trials and in $11 / 20(55 \%)$ of TS - trials, whereas guessing was limited (0/10 responses in CA trials). Nanostimulation induced 9.4 \pm 5.2 APs (mean \pm SD) during the $200 \mathrm{~ms}$ current injections. In NA trials, the animal responded in only $1 / 10$ (10\%) of the trials. In combination with threshold whisker stimulation lick responses, were observed in 14/21 (67\%) of TS + trials. Thus, the animal responded more often in TS + trials than in TS - trials. Because of the small effect sizes and the limited number of trials typically collected in behavioral single-cell-stimulation experiments (Houweling and Brecht, 2008; Doron et al., 2014), we assessed the statistical significance of single-cell stimulation effects at the population level.

For the entire population of barrel cortex cells $(n=167)$, we did not find a significant increase in response rates for TS+ versus TS - trials (Fig. 3A, $B$; TS + hits minus TS - hits; mean, $+0.7 \% ; t_{(166)}=0.62, p=0.54$, paired $t$ test). Reaction times to TS - stimuli were slower than those to EB stimuli (Fig. $3 C$ ). Nor did we find a difference in response rates for NA versus CA trials (Fig. 3B; mean, $+0.02 \% ; t_{(166)}=0.02, p=0.99$, paired $t$ test). These results suggest that, on average, nanostimulation had little 
A
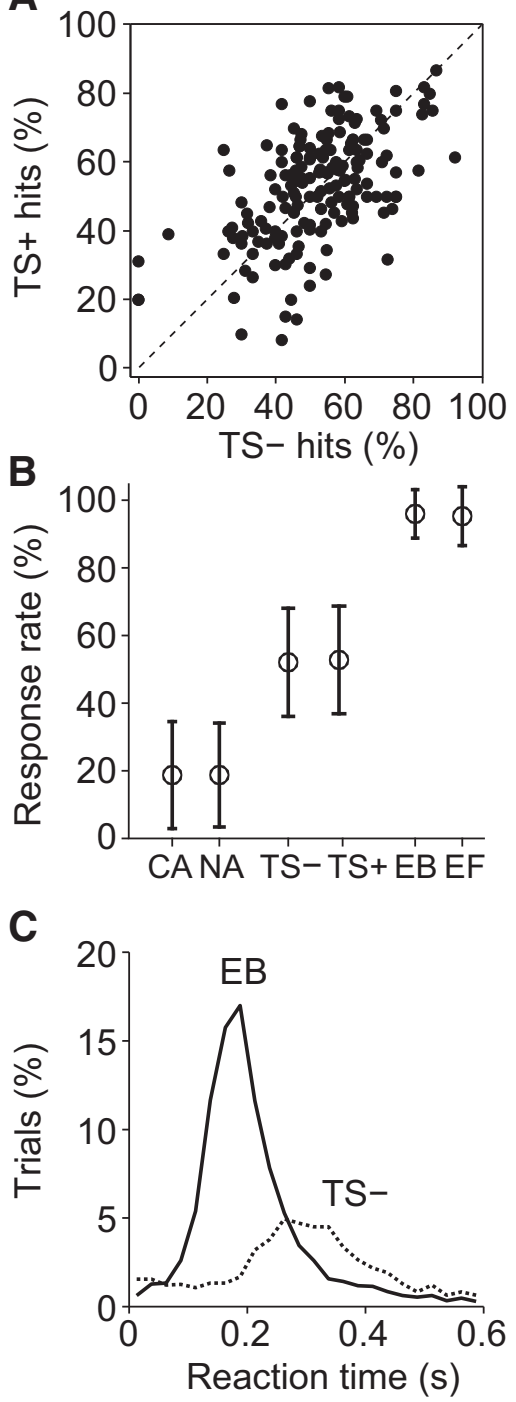

Figure 3. Undifferentiated population analysis. Single-cell stimulation does not affect mean response rates when all cells are considered as one large group $(n=167)$. $A$, Response rates (hits) in TS + trials versus TS - trials. $\boldsymbol{B}$, Average response rates across single-cell-stimulation experiments. Error bars indicate SDs. C, Average reaction time histograms for the two types of backward whisker stimulation trials ( $25 \mathrm{~ms}$ bins).

impact on detection performance. However, cell types likely have distinct roles in perception; therefore, we divided cells into several categories based on their physiological characteristics.

\section{Fast-spiking putative inhibitory neurons}

We first divided all neurons $(n=167)$ into FS putative inhibitory interneurons $(n=33)$ and non-FS putative excitatory neurons $(n=134)$ based on the width of the juxtacellular AP (Fig. 4A; Avermann et al., 2012) and maximum firing rate during nanostimulation (Houweling and Brecht, 2008; Doron et al., 2014; Fig. $4 B, C)$. The spike width histogram showed a bimodal distribution separated at about $0.5 \mathrm{~ms}$ (Fig. $4 A$ ); the maximum firing rate histogram showed a skewed distribution with a tail starting at about $200 \mathrm{~Hz}$. We therefore classified cells with spike width $<0.5$ $\mathrm{ms}$ and/or a maximum firing rate during stimulation of $>200 \mathrm{~Hz}$ as FS cells (Fig. 4C, black circles). Nanostimulation induced, on average, $12.2 \pm 6.3$ APs in FS cells during the $200 \mathrm{~ms}$ current injection. Surprisingly, pairing whisker stimulation with nanos- timulation of a single FS cell increased the detection rate for whisker stimulation by, on average, $6.3 \%$ (Fig. $4 D ; t_{(32)}=2.68$, $p=0.012$, paired $t$ test; bootstrapped 95\% CI, $1.9-10.3 \%)$, from $48.8 \%$ (TS - trials) to $55.1 \%$ (TS + trials). FS cells, as identified here, may represent two or more cell classes based on AP width (Fig. 4C). The mean effect on detection, however, was comparable for thin-spike $(\leq 0.5 \mathrm{~ms})$ and broad-spike $(>0.5 \mathrm{~ms})$ FS cells (thin spike, $+5.6 \%$; broad spike, $+6.8 \%$; $t_{(31)}=0.23, p=0.82$, two-sample $t$ test), and we therefore treated FS cells as a single group. Moreover, the sensory detection change, the difference between the response rate in TS + and TS - trials, depended little on the exact firing rate boundary in the range 170 to $300 \mathrm{~Hz}$ (data not shown), indicating that the positive effect of FS cells did not depend on their exact definition criteria.

To confirm that the detection change induced by single-FScell stimulation did not result from the inadvertent stimulation of neighboring neurons or other nonspecific effects, we injected current ( $25 \mathrm{nA}$, approximately fivefold the average current applied during nanostimulation) through the pipette into extracellular space instead of applying it to a neuron. These control experiments showed that the detection rate for whisker stimulation was unaffected ( $n=144$ experiments in 20 animals; TS + hits minus TS - hits; mean, $-1.1 \% ; t_{(143)}=0.98, p=0.33$, paired $t$ test; $\mathrm{CI},-3.3-0.7 \%)$. Alternatively, the increased detection rate in TS + trials might be due to a small perceptual effect of single-cell stimulation by itself (Figs. $4 E, 6 B$ ). In that case one would expect a small rightward shift of the reaction time histogram for TS+ trials (Fig. $4 F$ ), since reaction times decreased with stimulus detectability (Fig. 3C) and NA trials yielded lower response rates than TS - trials (Fig. 3B). However, median reaction times of hits were similar for TS + and TS - trials (296 vs $297 \mathrm{~ms} ; p=0.61$, Wilcoxon rank sum test). We also compared for FS cells the effects of nanostimulation in whisker stimulation trials and in trials without whisker stimulation (NA and CA trials). Response rates were similar in NA and CA trials (Figs. 4E, 6B; NA hits minus CA hits; mean, $+2.8 \% ; t_{(32)}=1.28, p=0.21$, paired $t$ test). Additionally, if detection of nanostimulation alone contributed to the increased detection rate in TS + trials, a positive relationship between the size of the sensory detection increase and the difference in response rate between NA and CA trials would be expected. Instead, a small, nonsignificant, negative correlation was found ( $r=-0.24, p=0.19$; Fig. $4 G$ ), suggesting that the sensory detection increase induced by single-FS-cell stimulation during whisker stimulation was due to alteration of the neural representation of the whisker stimulus.

The size of the sensory detection change induced by single-FScell stimulation did not correlate with the number of added APs during nanostimulation (in NA trials, $r=-0.18$, $p=0.33$ ), recording depth $(r=-0.02, p=0.93)$ or baseline firing rate $(r=$ $-0.07, p=0.68)$. The number of APs in a $100 \mathrm{~ms}$ poststimulus window were not statistically different for hit trials and miss trials of FS cells, both for TS - trials (hits minus misses, $0.29 \pm 1.3$ $($ mean $\pm \mathrm{SD}) ; p=0.22, t_{(31)}=1.25$, paired $t$ test) and for TS + trials (hits minus misses, $0.23 \pm 3.6 ; p=0.71, t_{(32)}=0.38$, paired $t$ test). We cannot exclude that another, more optimal time window (Stüttgen and Schwarz, 2008) would have yielded different results. In addition, because of the small number of cells, the limited number of hit/miss trials, the low firing rates, and the sensitivity to outliers, we cannot exclude that a protocol aimed at specifically testing for the presence of choice probability would have yielded different results.

The irregularity of the spike trains induced by single-FS-cell stimulation during TS + trails, quantified as the $\mathrm{CV}_{\text {ISI }}$, did display 

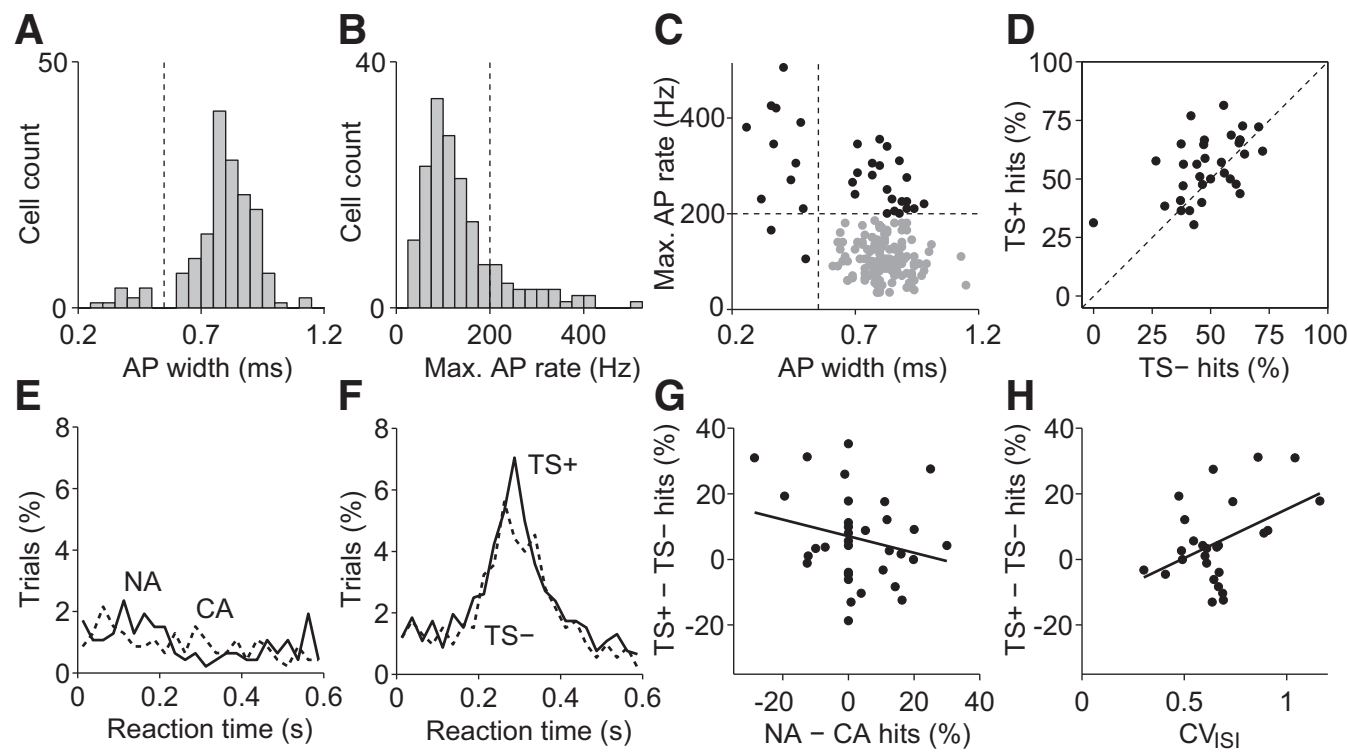

Figure 4. Initiation of action potentials in single fast-spiking inhibitory neurons induces a sensory detection increase. $A$, Bimodal distribution of AP widths across cells ( $n=167)$. Neurons with AP widths (measured peak-to-trough) less than or equal to $0.5 \mathrm{~ms}$ were classified as FS cells. B, Distribution of maximum firing rates across cells during nanostimulation trials. Note that no special effort was made to fire cells at maximum rates. Neurons that fired 40 APs or more (i.e., $\geq 200 \mathrm{~Hz}$; vertical dotted line) during at least one of the NA trials were classified as FS cells. $C$, Joint distribution of maximum firing rates and AP widths. Cells with maximum firing rate of below $200 \mathrm{~Hz}$ and AP width larger than $0.5 \mathrm{~ms}$ were classified as putative excitatory neurons (gray circles), the other cells as FS putative inhibitory neurons (black circles). $\boldsymbol{D}$, Response rates (hits) in TS + trials versus TS - trials in experiments on FS cells $(n=33)$. Single-cell stimulation increased the mean response rate by $6.3 \%$. $\boldsymbol{E}$, Average reaction time histograms for NA and CA trials ( $25 \mathrm{~ms}$ bins). $\boldsymbol{F}$, Average reaction time histograms for TS+ and TS - trials ( $25 \mathrm{~ms}$ bins). $\boldsymbol{G}$, The response change induced by nanostimulation alone (NA hits minus (A hits) was not correlated with the sensory detection change induced in whisker stimulation trials (TS+ hits minus TS - hits). Data in $\boldsymbol{D}-\mathbf{G}$ are from experiments on FS cells $(n=33)$. $\boldsymbol{H}$, Spike train irregularity during nanostimulation displayed a positive correlation with sensory detection change $(n=26 \mathrm{FS}$ cells).

a positive correlation with the size of the sensory detection change (Fig. $4 H ; r=0.45, p=0.022$, not significant after correction for multiple comparisons; $m=6$ ), as was reported before in a different type of single-cell-stimulation experiment (Doron et al., 2014). $\mathrm{CV}_{\text {ISI }}$ did not vary with AP width $(r=-0.22, p=0.27)$. However, the positive correlation between spike irregularity and detection change might point toward a special role for a specific subtype of FS interneurons, as the irregularity of AP firing during current injections is used as a parameter in some classification schemes (Markram et al., 2004). Alternatively, animals may be sensitive to the temporal patterning of spike trains elicited in single neurons (Doron et al., 2014). In summary, we find that, counterintuitively, inducing APs in a single FS putative interneuron can enhance the detection of threshold whisker stimuli.

\section{Putative excitatory neurons}

We next performed a population analysis on putative excitatory neurons (Fig. 4C, gray circles; $n=134$ of 167 cells). Nanostimulation induced, on average, $7.3 \pm 3.8 \mathrm{APs}$ in excitatory cells during the $200 \mathrm{~ms}$ current injections. In contrast to the effects of single-FS-cell stimulation, pairing whisker stimulation with stimulation of single excitatory neurons did not affect the TS detection rate when excitatory neurons were considered as one large group (sensory detection change, $-0.7 \%$; $t_{(133)}=0.53, p=$ 0.60 ; 95\% CI, $-3.1-1.4 \%$; Fig. $5 A$ ). However, the excitatory neurons did not constitute a homogeneous population, as cells were recorded across all cortical layers and whisker stimulation evoked a wide range of response patterns, including excitation, inhibition, and nonresponsiveness (Fig. $5 B, E, F$ ). Moreover, some cells may have been located outside the $\mathrm{C} 1$ barrel column despite our targeting efforts. As found for FS cells, the sensory detection change induced by stimulation of single excitatory neurons did not vary with the number of added APs during nanostimulation (in NA trials, $r=0.13, p=0.12)$ or recording depth $(r=0.04$, $p=0.62$ ).

The nature of a neuron's sensory response depends on the input it receives from other cortical neurons and from afferent inputs carrying sensory information. To determine whether a neuron's sensory response identity affected its ability to induce a sensory detection change, we first characterized neuronal responses during EB trials using an ROC analysis based on spike counts in a sliding $25 \mathrm{~ms}$ window. A previous study showed that $25 \mathrm{~ms}$ is the optimal window duration for decoding the presence or absence of whisker stimuli, which were identical to those used in our study, from spike counts in barrel cortex (Stüttgen and Schwarz, 2008). To obtain a temporal response profile for each neuron, we quantified firing rate changes from baseline by calculating a sensitivity index (auROC) at each time bin (Cohen et al., 2012). Sensitivity values of $>0.5$ indicate increased AP firing relative to baseline, whereas values of $<0.5$ indicate decreased AP firing. We then classified these response profiles using PCA followed by $k$ means clustering (Fig. $5 B, C$ ). The four clusters that we obtained were characterized by distinct temporal response profiles (Figs. $5 E, F, 6 A$ ). The first cluster consisted of spontaneously active cells that decreased AP firing during whisker stimulation [inhibited (I) neurons; $n=19$ ]. The second and third clusters consisted of cells that increased AP firing during whisker stimulation, either vigorously (HS neurons; $n=6$ ), typically with multiple APs, or relatively weakly [weak-responder (WR) neurons; $n=16]$, typically with a single AP in a fraction of trials. HS neurons produced, on average, 3.1 APs per trial during the first 50 ms following high-velocity (EB) whisker stimulation (range, 1.2 7.6 APs; corrected for background rate), whereas WR neurons produced 0.45 APs per trial (range, $-0.18-1.4$ APs). HS neurons responded equally vigorously to high-velocity whisker stimuli in the backward and forward directions (mean of 3.2 APs per EF 
A
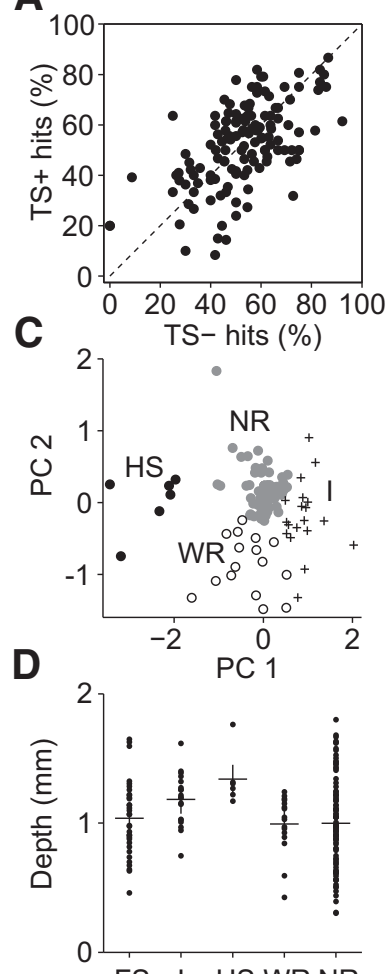

B

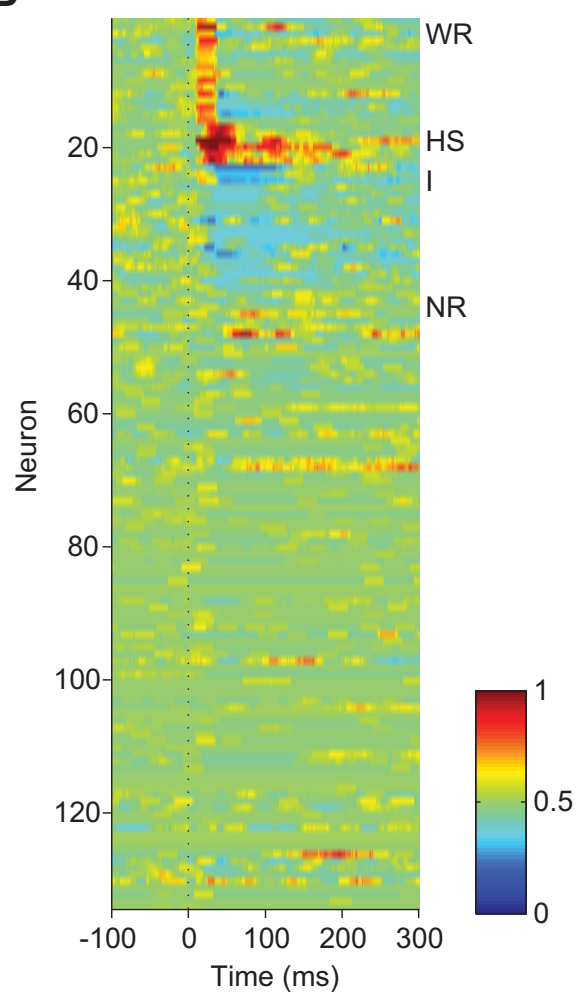

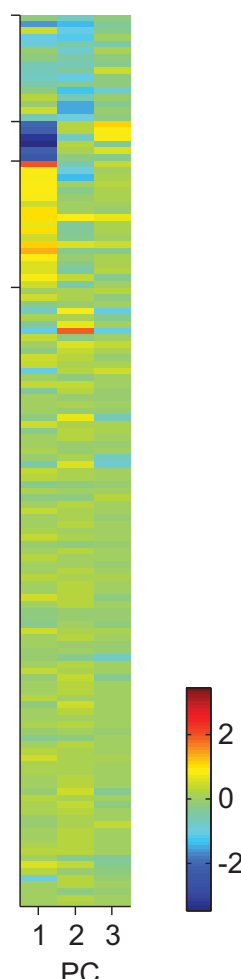

$\mathrm{PC}$
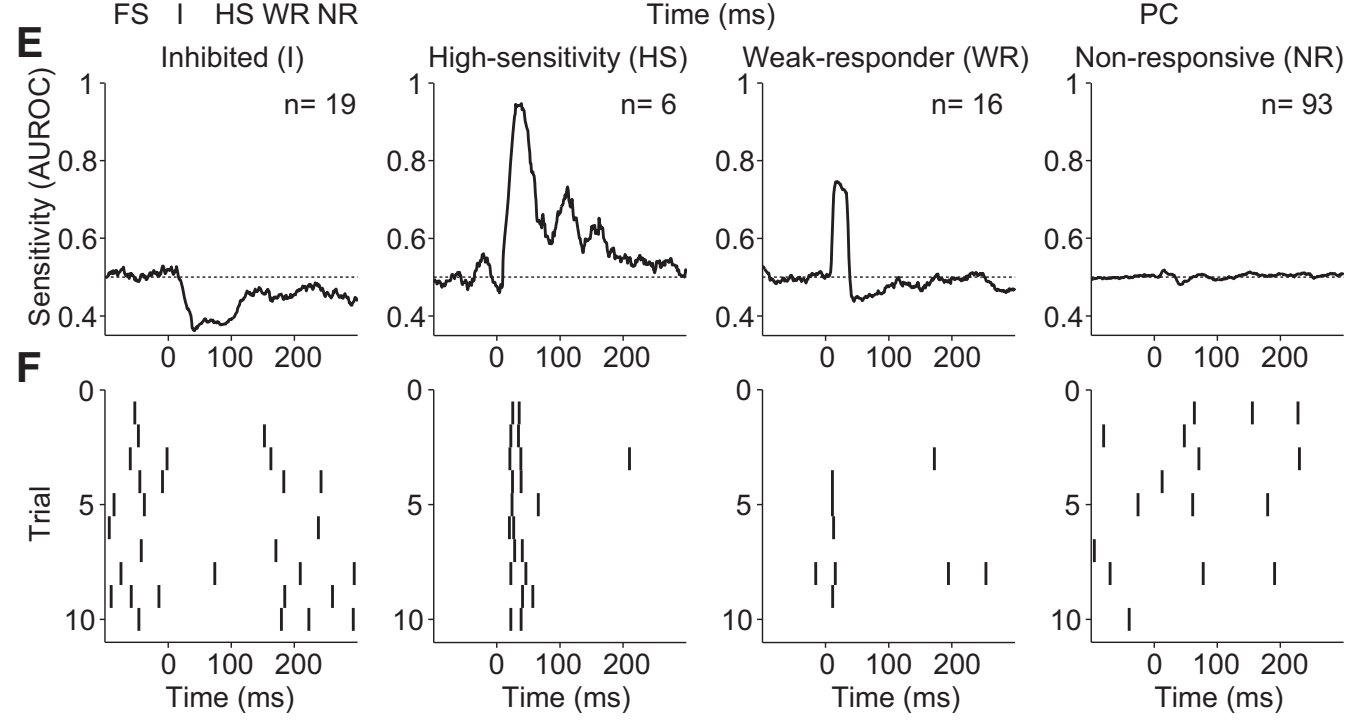

Figure 5. Putative excitatory cells can be subdivided into four whisker-response categories. $A$, Response rates (hits) in TS + trials versus TS - trials in all experiments on putative excitatory neurons $(n=134)$. Single-cell stimulation did not affect the mean response rate when excitatory neurons were considered as one large group. $\boldsymbol{B}$, Temporal response profiles of excitatory neurons to EB whisker stimulation and their first three principal component scores. C, Temporal response profiles of excitatory neurons to EB whisker stimulation were classified into four clusters $(I$ cells, $n=$ 19, plus signs; HS cells, $n=6$, black dots; WR cells, $n=16$, open circles; NR cells, $n=93$, gray dots). Axes represent the first two principal component scores of the response profiles. $\boldsymbol{D}$, Depth meter readings for individual neurons (dots) together with group averages (plus signs). $\boldsymbol{E}$, Average temporal response profiles for the four different clusters, with stimulus onset at time 0 . HS neurons reached maximal sensitivity ( $39 \mathrm{~ms}$ after stimulus, endpoint of $25 \mathrm{~ms}$ bin) later than WR neurons ( $16 \mathrm{~ms}$ after stimulus). Gray regions indicate bootstrapped $95 \%$ confidence intervals. $\boldsymbol{F}$, Raster plots depicting spike responses in 10 EB whisker stimulation trials for, from left to right, an example I cell, HS cell, WR cell, and NR cell.

trial; 0-50 ms after stimulus). In both WR and HS neurons, the spontaneous activity consisted of single, isolated APs; spontaneous bursts were not apparent. The fourth and largest cluster consisted of cells that were not or only very weakly affected by whisker stimulation [nonresponsive (NR) neurons; $n=93$ ], in line with other studies that reported a large fraction of nonresponsive neurons in the principal barrel column (de Kock et al., 2007; Kerr et al., 2007; O'Connor et al., 2010; Sachidhanandam et al., 2013; Clancy et al., 2015; Reyes-Puerta et al., 2015).
Only HS neurons showed discernable responses to threshold whisker stimulation (Fig. $6 B$; HS, mean of 0.77 APs per TS - trial; WR, 0.028 APs per TS - trial), restricted to the first $100 \mathrm{~ms}$ following stimulation. In each of the four cell clusters, the increase in spike rate evoked by nanostimulation had a similar temporal profile (Fig. $6 B$ ), and the number of induced APs during nanostimulation was similar (NA trials, $\chi_{(3)}^{2}=2.9, p=0.41$, KruskalWallis test; TS+ trials, Fig. $6 B)$ as well as their trial-by-trial variability (NA trials, CV, $0.85 \pm 0.43($ mean $\pm \mathrm{SD}) ; \chi_{(3)}^{2}=1.6$, 

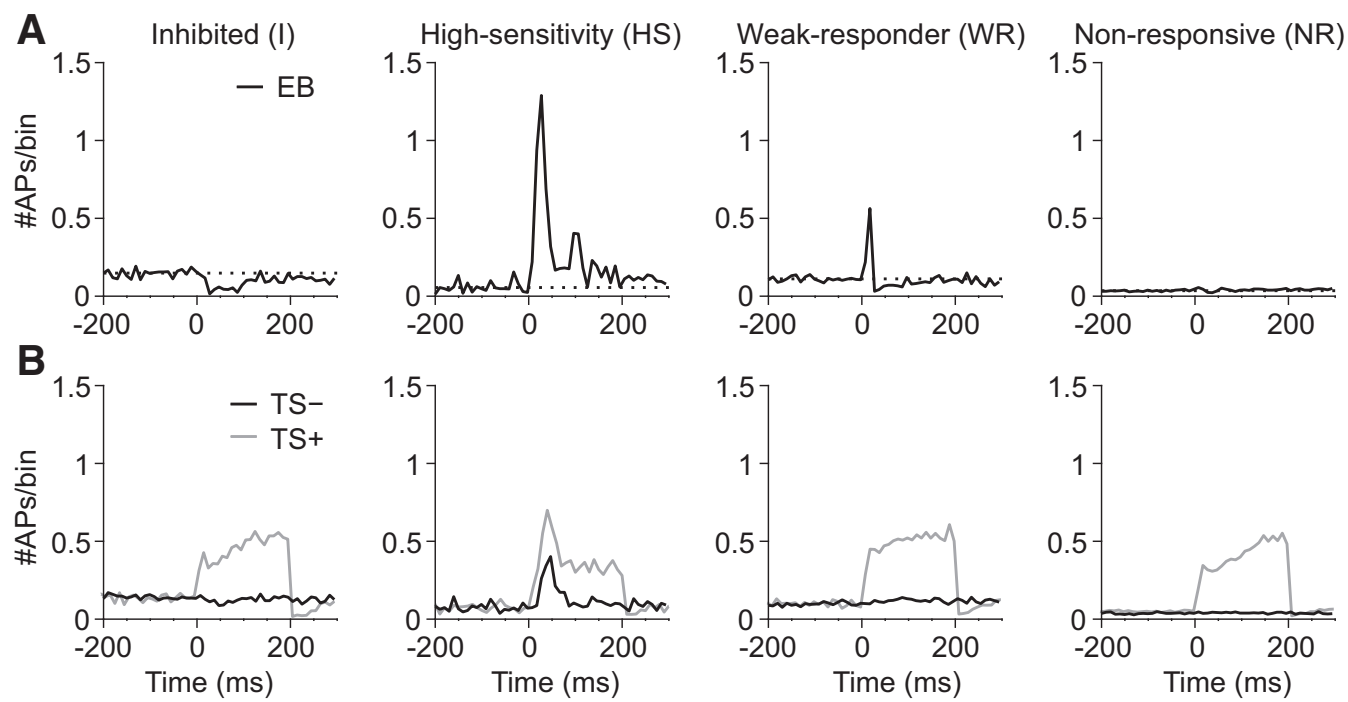

Figure 6. Average poststimulus time histograms for the four different clusters of excitatory cells. $A$, Same data as in Figure $5 E$ depicting sensory responses in EB trials but now represented as average PSTHs with $10 \mathrm{~ms}$ bins. Stimulus onset is at time 0 . B, Same as $A$, but for TS - trials (black lines) and TS + trials (gray lines).

$p=0.67$, Kruskal-Wallis test). We therefore conclude that the impact of nanostimulation on firing was similar across the four cell clusters.

We next investigated the impact of single-cell stimulation on whisker movement detection. The sensory detection change induced by nanostimulation differed across cell clusters $\left(\chi_{(3)}^{2}=\right.$ $10.3, p=0.017$, Kruskal-Wallis test; Fig. 7A). Single-cell stimulation induced a significant sensory detection change in highsensitivity excitatory neurons, but not in inhibited neurons, weak-responder neurons, or nonresponders (after correction for multiple comparisons, $m=4$; Fig. 7A). Nanostimulation of HS neurons increased the detection rate of threshold whisker stimuli by, on average, $14.7 \%\left(t_{(5)}=4.25, p=0.0081\right.$, paired $t$ test $)$. In contrast, nanostimulation of I neurons, WR neurons or NR cells had little impact on TS detection rates $\left(\mathrm{I},-3.5 \%, t_{(18)}=1.00, p=\right.$ 0.33 ; WR, $+3.8 \%, t_{(15)}=1.26, p=0.23 ; \mathrm{NR},-1.9 \%, t_{(92)}=1.21$, $p=0.23$, paired $t$ test). The number of APs in a $100 \mathrm{~ms}$ poststimulus window were not statistically different for hit trials and miss trials of HS cells, both for TS - trials (hits minus misses, $0.28 \pm$ $1.4($ mean $\pm \mathrm{SD}) ; p=0.64, t_{(5)}=0.50$, paired $t$ test $)$ and for TS + trials (hits minus misses, $0.33 \pm 2.1 ; p=0.72, t_{(5)}=0.38$, paired $t$ test). We cannot exclude that another, more optimal time window (Stüttgen and Schwarz, 2008) would have yielded different results. In addition, because of the small number of cells, the limited number of hit/miss trials, the low firing rates, and the sensitivity to outliers, we cannot exclude that a protocol aimed at specifically testing for the presence of choice probability would have yielded different results. Nanostimulation of excitatory neurons alone without whisker stimulation did not affect response rates (NA hits minus CA hits; mean, $-0.7 \%$; $p=0.65, t_{(133)}=$ 0.46 , paired $t$ test), which did not differ across cell clusters (Fig. $7 B ; \chi_{(3)}^{2}=0.7, p=0.87$, Kruskal-Wallis test).

Although WR neurons contribute to the total spike output of the barrel column induced by whisker stimulation, only in HS neurons, and not in WR neurons, did nanostimulation induce a large sensory detection change. HS neurons differed from WR neurons in at least two aspects other than their responses to whisker stimulation. First, HS neurons were recorded at different depths than WR neurons ( $p=0.0017$, Wilcoxon rank sum test). Based on depth meter readings, HS neurons were located in in-
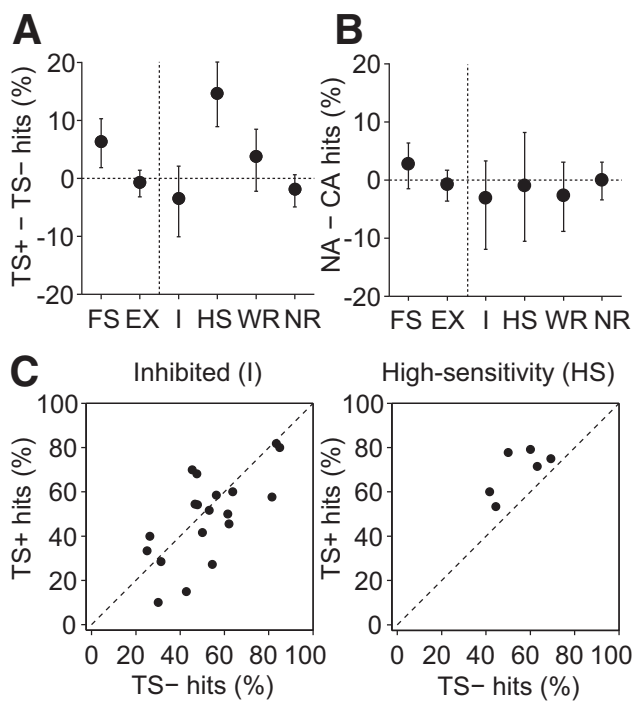

High-sensitivity (HS)
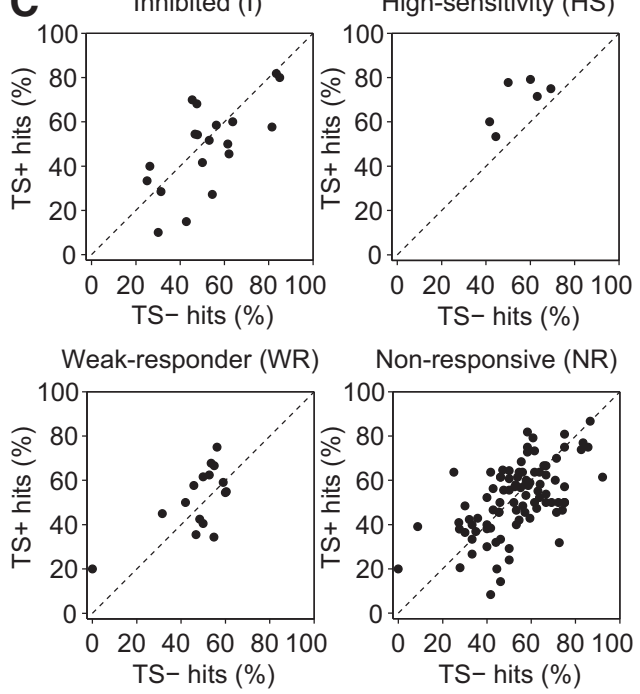

Figure 7. Initiation of action potentials in single high-sensitivity excitatory neurons induces a sensory detection increase. $\boldsymbol{A}$, The sensory detection change induced by single-cell stimulation differed across excitatory cell clusters. $\boldsymbol{B}$, The effect of single-cell stimulation by itself (NA hits minus (A hits) did not differ across excitatory cell clusters. $\boldsymbol{A}, \boldsymbol{B}$, Error bars indicate bootstrapped $95 \%$ confidence intervals. Mean single-cell-stimulation effects are also shown for FS inhibitory cells and all excitatory neurons grouped together (EX). $C$, Response rates in TS + trials versus TS - trials in experiments on I, HS, WR, and NR neurons. Nanostimulation increased the mean response rate when applied to HS cells, but not when applied to I, WR, or NR cells.

fragranular layers, whereas most WR neurons were recorded at more superficial depths (Fig. 5D). Second, the spontaneous firing rates of HS cells were lower than those of WR neurons (Fig. 6; $p=$ 0.043 , Wilcoxon rank sum test; HS cells, median, $1.1 \mathrm{~Hz}$; range, 
A
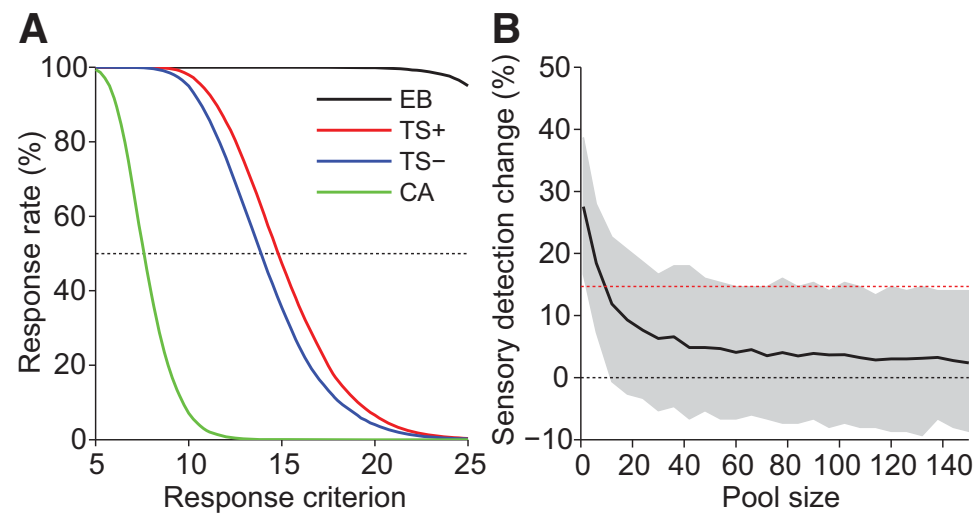

Figure 8. Threshold detection model. $\boldsymbol{A}$, Response rates for the four different trial types in the model when the decision pool included $12 \mathrm{HS}$ cells. Single-cell stimulation was applied to one of the model neurons (TS + trials). The response criterion was set to obtain a response rate of $50 \%$ in TS - trials. B. The sensory detection change (TS + hits minus TS - hits) induced by singleHS-cell stimulation decreased as a function of the number of HS cells included in the decision pool. The black line indicates the mean sensory detection change in the model for a set of six single-cell-stimulation experiments (1 per HS cell). The red line indicates the mean sensory detection change obtained in behavioral experiments on HS cells. The gray area represents the $95 \%$ confidence interval for the mean sensory detection change in the model. The decrease of sensory detection change with pool size was well described by a double exponential decay $\left(r^{2}>0.99\right)$ or a rational function of degree one for both the numerator and denominator $\left(r^{2}>0.99\right)$

0.3-2.8 Hz; WR cells, median, 6.9 Hz; range, 0.5-18.3 Hz). These results indicate that the perception of whisker movement depends on neurons in the barrel cortex with specific anatomical and physiological characteristics.

\section{Detection model}

Our single-cell-stimulation results suggest that the spike discharges of a pool of high-sensitivity neurons have a disproportionally large impact on sensory detection. The larger this pool, the smaller the contribution of individual neurons to the summed pool activity, as well as the expected sensory detection change induced by single-cell stimulation, will be. To estimate the pool size that matches our experimental observations, we constructed a simple threshold detection model (Cook and Maunsell, 2002; Stüttgen and Schwarz, 2010) based on the spike responses of HS neurons and investigated how the sensory detection change induced by single-cell stimulation depended on the number of HS cells included in the pool. In this model, the spike discharges of pool neurons were summed to construct a population peristimulus time histogram (PSTH) and then filtered through a leaky integrator with exponential decay (see Materials and Methods). This signal was then used to generate artificial behavioral responses based on simple threshold crossings. As expected, we found that the sensory detection change induced by single-HS-cell stimulation decreased with pool size (Fig. 8). A pool size of $\sim 10 \mathrm{HS}$ cells produced a sensory detection change that most closely matched our experimental estimate of sensory detection change, whereas pool sizes of 60 or more HS cells consistently yielded lower values. Together, these results suggest that the spike discharges of a small pool of high-sensitivity neurons can be sufficient to detect whisker stimuli.

\section{Discussion}

Here we studied the impact of single cortical neurons on sensory detection. A linear decoder of a sensory stimulus functions optimally if it weights the sensor neurons by their sensitivity (Jazayeri and Movshon, 2006; Haefner et al., 2013). We found direct supporting evidence that this is the case in the rat barrel cortex, since nanostimulation of single neurons that responded well to whis- ker stimulation enhanced the detection of very small whisker movements, whereas nanostimulation of neurons that showed very little or no response to whisker stimulation did not modify detection of small whisker movements. Apart from these highsensitivity neurons, stimulation of single putative interneurons also enhanced whisker movement detection, indicating their causal involvement in sensory decision making.

\section{How did nanostimulation enhance whisker movement detection?}

The most likely mechanism underlying the enhancement of whisker motion detection by nanostimulation is that nanostimulation increased the amount of whisker motion evidence for the decision pool of whisker motion detection. By presenting the different stimuli in blocks, in pseudorandom order, we minimized the chance that the enhancing effects of nanostimulation were spurious, for example, due to stochastic fluctuations in the attention or arousal state of the animal. A second possibility is that nanostimulation was directly detected as such by the rat, and acted as a general alerting or timing signal, or was even associated with the reward. Animals trained to detect microstimulation applied to barrel cortex can to some extent also detect the stimulation of a single neuron in the barrel cortex (Houweling and Brecht, 2008; Doron et al., 2014), and in theory these detections could be independent of the whisker stimulation. In the current study, rats were not trained to detect electrical stimulation. Also, the detection rate was not higher in trials in which nanostimulation was presented alone than in catch trials, suggesting that nanostimulation alone did not induce a detection bias. Interestingly, in a recent study on the impact of microstimulation on visual motion detection in monkeys, the monkeys did not adjust their strategy in the trials in which microstimulation was present even though this would lead to more rewards, suggesting that detecting microstimulation is quite hard within the context of a sensory task (Fetsch et al., 2014), whereas other studies have shown that microstimulation can be a salient stimulus in a microstimulation detection task (Bartlett and Doty, 1980; Butovas and Schwarz, 2007; Murphey and Maunsell, 2007). We therefore consider it most likely that nanostimulation enhanced detection by adding whisker motion evidence to the pool of neurons that encode this information. The observation that the firing of a single cell in the barrel cortex can raise the information available in the whisker sensory system sufficiently to significantly increase detection of whisker movements provides new information about the way this information is decoded.

\section{The size of the decision pool for whisker motion perception} In the HS neurons, the addition of about seven spikes by nanostimulation was sufficient to improve whisker motion detection. The relatively large impact of HS neurons on whisker motion detection is in agreement with both the lower envelope principle, which states that decisions are based on a small number of the most sensitive neurons and little influenced by the spikes of the many other less sensitive neurons (Barlow, 1972), and the idea that the decision decoder works optimally, since a characteristic 
of an optimal decoder is that it weighs sensory neurons by their sensitivity (Jazayeri and Movshon, 2006; Haefner et al., 2013). Our study lacks the precision to firmly exclude a small role of the WR neurons in the decision pool, which would allow us to discriminate between both scenarios.

A simple threshold detection model (Cook and Maunsell, 2002; Stüttgen and Schwarz, 2010) based on actual HS neuron responses showed that a decision pool of only $10 \mathrm{HS}$ neurons was sufficient to account for the observed impact of HS neurons on whisker motion detection. This small size is in line with the findings of Stüttgen and Schwarz (2008), who showed, using a similar whisker stimulation detection task, that the rat's performance could be matched by a pooling model containing as little as five of the most sensitive neurons, as well as our finding that stimulation of a single FS cell affected the detection rate of whisker stimuli. The threshold detection model assumed linear summation of spikes, the absence of noise correlations, and no impact of nanostimulation on the firing of other neurons in the decision pool. Unitary connections between cortical pyramidal cells are typically small in barrel cortex $(<1 \mathrm{mV})$, and stimulation of single pyramidal neurons induces weak local network effects dominated by inhibition (Kapfer et al., 2007; Silberberg and Markram, 2007; Lefort et al., 2009; Kwan and Dan, 2012; Jouhanneau et al., 2015). In addition, $S 1$ has relatively low noise correlations (Reyes-Puerta et al., 2015; Kwon et al., 2016). Even though these observations thus support the assumptions of the model, it seems rather fortuitous that we recorded from cells that could enhance sensory detection. Also, a two-photon calcium imaging study suggested a high degree of redundancy in the code for whiskerbased object localization within barrel cortex, again suggesting that the decision pool might be larger (O'Connor et al., 2010).

An alternative possibility to explain the observed impact of nanostimulation on whisker motion detection is that the motion detection decoder acts in a nonlinear manner (Shamir and Sompolinsky, 2004). This could be realized if the decoding weight of contributing neurons increased with firing frequency, for example, if their output showed strong synaptic facilitation (Lisman, 1997), in combination with the intrinsic nonlinearity of the spike generation mechanism in target neurons (Silver, 2010). Physiologically, such high-frequency firing might be produced by nonlinear interactions between synaptic inputs (Larkum, 2013). The short integration time observed for whisker motion detections in a similar behavioral paradigm as used here (Stüttgen and Schwarz, 2010) is in agreement with this possibility, and with the apparent lack of an effect of WR neurons on detection.

\section{How did high-sensitivity neurons enhance whisker motion detection?}

Large-scale recording and imaging approaches suggest that the sensory evidence represented in early sensory cortical areas is gradually integrated across downstream cortical areas including premotor cortices (de Lafuente and Romo, 2006; Guo et al., 2014). Both their recording depths and response properties suggest that the HS neurons correspond to layer 5b (thick-tufted) pyramidal neurons (de Kock et al., 2007). Layer 5b pyramidal cells in barrel cortex project to pyramidal neurons and interneurons within the same barrel. In addition, layer $5 \mathrm{~b}$ neurons project to other cortical areas, including S2 and M1, as well as to subcortical nuclei. From these areas there are connections to brain areas involved in motor preparation and licking (for review, see Bosman et al., 2011; Guo et al., 2014). Layer 5b neurons are thus in a good position to make a relatively large contribution to whisker motion detection.
Burst-like, persistent firing in the layer $5 \mathrm{~b}$ neurons, as induced here by nanostimulation, may normally result from the nonlinear interaction of cortical feedback inputs to layer 1 with basal inputs, leading to calcium spikes in their distal dendrites (Schiller et al., 1997; Larkum et al., 2004). Interestingly, these calcium spikes, and the resultant persistent firing (Manita et al., 2015), have been proposed to play an important role in whisker movement perception (Takahashi et al., 2016), which is thus in good agreement with our present results.

\section{How did putative interneurons enhance whisker motion detection?}

Interneurons are in a good position to influence whisker detection, since they contain a relatively large amount of information about whisker stimuli (Reyes-Puerta et al., 2015). However, the finding that nanostimulation of fast-spiking putative interneurons enhanced whisker perception was still unexpected considering earlier psychophysical experiments in barrel cortex. Parvalbumin (PV)-expressing neurons, which approximately correspond to fastspiking interneurons (Markram et al., 2004), fire less in trials in which strong, magnetically induced whisker motion is detected (Sachidhanandam et al., 2016). Whisker motion detection improves when multiple PV neurons in barrel cortex are optogenetically inhibited (Sachidhanandam et al., 2016) and gets worse when multiple PV or somatostatin interneurons are optogenetically stimulated (Guo et al., 2014; Takahashi et al., 2016; Yang et al., 2016).

We classified neurons as fast-spiking cells based on spike duration and firing rate. In our previous studies, these criteria correctly predicted excitatory and inhibitory neuron morphologies in small samples of recovered cells (Houweling and Brecht, 2008; Doron et al., 2014). Even though this classification method will not be without errors (D. Kim et al., 2016), our sample is likely to have included the major different classes of fast-spiking interneurons (Feldmeyer et al., 2018; Hattori et al., 2017).

One way enhancement of whisker motion detection by nanostimulation of fast-spiking interneurons may have acted is via disinhibition or postinhibitory rebound of excitatory neurons. The latter might be an attractive possibility, especially since longlatency spikes may be relatively important for detection performance (Sachidhanandam et al., 2013; Yamashita and Petersen, 2016). However, despite widespread connectivity from PV interneurons to local interneurons, PV interneurons have a predominantly inhibitory action on pyramidal neurons (Atallah et al., 2012) leading rarely to disinhibition of excitatory neurons (Wilson et al., 2012). Vasoactive Intestinal Peptide (VIP) interneurons have been reported to mediate disinhibition (Lee et al., 2013), but VIP-expressing interneurons are generally not fast spiking and constitute only a small fraction of the interneurons in the barrel cortex. It therefore seems unlikely that fast-spiking interneurons enhanced detection by adding spikes to the decision pool of S1 neurons.

A more likely explanation for how fast-spiking interneurons can enhance detection is suggested by experiments in auditory cortex, in which photostimulation of PV neurons induced strong suppression of spontaneous firing but relatively weak reduction of tone-evoked responses (Hamilton et al., 2013). If single-FS-cell stimulation in barrel cortex inhibits spontaneous firing but leaves whisker-evoked responses largely intact, and if decision pool activity is compared to activity of nonpool neurons instead of a fixed threshold (Bosking and Maunsell, 2011), then nanostimulation of FS cells can lead to increased detection by increasing the signal-to-noise ratio of whisker-evoked responses. Other possible ways in which interneurons may have improved whisker motion 
detection are through changing statistical network properties by reducing the variance in trial to trial fluctuations or by reducing noise correlations (reviewed in Kohn et al., 2016). Recent results from other cortical areas also support a possible enhancing effect of interneurons on sensory processing. Photostimulation of PV neurons may increase orientation selectivity in visual cortex (Atallah et al., 2012; Lee et al., 2012) and increase attentional processing in medial prefrontal cortex (H. Kim et al., 2016).

\section{Further elucidating the identity of the decision pool for whisker motion detection}

By facilitating the identification of individual cortical neurons (Lima et al., 2009; Muñoz et al., 2014; Pala and Petersen, 2015), optogenetics could help to further dissect the contribution of different cell types to decision making, especially when used in combination with imaging techniques that allow us to assess the impact different firing patterns of a stimulated neuron have on other neurons. However, the current study already demonstrates a unique and powerful property of the single-cell-stimulation approach: by targeting neurons of a selected sensory response type, sensory detection can be significantly manipulated by stimulation of a single cortical neuron, demonstrating their causal involvement in sensory perception.

\section{References}

Afraz SR, Kiani R, Esteky H (2006) Microstimulation of inferotemporal cortex influences face categorization. Nature 442:692-695. CrossRef Medline

Atallah BV, Bruns W, Carandini M, Scanziani M (2012) Parvalbuminexpressing interneurons linearly transform cortical responses to visual stimuli. Neuron 73:159-170. CrossRef Medline

Avermann M, Tomm C, Mateo C, Gerstner W, Petersen CC (2012) Microcircuits of excitatory and inhibitory neurons in layer $2 / 3$ of mouse barrel cortex. J Neurophysiol 7:3116-3134. Medline

Barlow HB (1972) Single units and sensation: a neuron doctrine for perceptual psychology? Perception 1:371-394. CrossRef Medline

Bartlett JR, Doty RW (1980) An exploration of the ability of macaques to detect microstimulation of striate cortex. Acta Neurobiol Exp (Wars) 40:713-727. Medline

Bosking WH, Maunsell JH (2011) Effects of stimulus direction on the correlation between behavior and single units in area MT during a motion detection task. J Neurosci 31:8230-8238. CrossRef Medline

Bosman LW, Houweling AR, Owens CB, Tanke N, Shevchouk OT, Rahmati N, Teunissen WH, Ju C, Gong W, Koekkoek SK, De Zeeuw CI (2011) Anatomical pathways involved in generating and sensing rhythmic whisker movements. Front Integr Neurosci 5:53. Medline

Britten KH, Newsome WT, Shadlen MN, Celebrini S, Movshon JA (1996) A relationship between behavioral choice and the visual responses of neurons in macaque MT. Vis Neurosci 13:87-100. CrossRef Medline

Brody CD, Hanks TD (2016) Neural underpinnings of the evidence accumulator. Curr Opin Neurobiol 37:149-157. CrossRef Medline

Butovas S, Schwarz C (2007) Detection psychophysics of intracortical microstimulation in rat primary somatosensory cortex. Eur J Neurosci 25: 2161-2169. CrossRef Medline

Clancy KB, Schnepel P, Rao AT, Feldman DE (2015) Structure of a single whisker representation in layer 2 of mouse somatosensory cortex. J Neurosci 35:3946-3958. CrossRef Medline

Cohen JY, Haesler S, Vong L, Lowell BB, Uchida N (2012) Neuron-typespecific signals for reward and punishment in the ventral tegmental area. Nature 482:85-88. CrossRef Medline

Cook EP, Maunsell JH (2002) Dynamics of neuronal responses in macaque MT and VIP during motion detection. Nat Neurosci 5:985-994. CrossRef Medline

de Kock CP, Bruno RM, Spors H, Sakmann B (2007) Layer- and cell-typespecific suprathreshold stimulus representation in rat primary somatosensory cortex. J Physiol 581:139-154. CrossRef Medline

de Lafuente V, Romo R (2006) Neural correlate of subjective sensory experience gradually builds up across cortical areas. Proc Natl Acad Sci U S A 103:14266-14271. CrossRef Medline
Ditterich J, Mazurek ME, Shadlen MN (2003) Microstimulation of visual cortex affects the speed of perceptual decisions. Nat Neurosci 6:891-898. CrossRef Medline

Doron G, von Heimendahl M, Schlattmann P, Houweling AR, Brecht M (2014) Spiking irregularity and frequency modulate the behavioral report of singleneuron stimulation. Neuron 81:653-663. CrossRef Medline

Feldmeyer D, Qi G, Emmenegger V, Staiger JF (2018) Inhibitory interneurons and their circuit motifs in the many layers of the barrel cortex. Neuroscience 368:132-151. Medline

Fellous JM, Tiesinga PH, Thomas PJ, Sejnowski TJ (2004) Discovering spike patterns in neuronal responses. J Neurosci 24:2989-3001. CrossRef Medline

Fetsch CR, Kiani R, Newsome WT, Shadlen MN (2014) Effects of cortical microstimulation on confidence in a perceptual decision. Neuron 83 : 797-804. CrossRef Medline

Gold JI, Shadlen MN (2007) The neural basis of decision making. Annu Rev Neurosci 30:535-574. CrossRef Medline

Guo ZV, Li N, Huber D, Ophir E, Gutnisky D, Ting JT, Feng G, Svoboda K (2014) Flow of cortical activity underlying a tactile decision in mice. Neuron 81:179-194. CrossRef Medline

Haefner RM, Gerwinn S, Macke JH, Bethge M (2013) Inferring decoding strategies from choice probabilities in the presence of correlated variability. Nat Neurosci 16:235-242. CrossRef Medline

Hamilton LS, Sohl-Dickstein J, Huth AG, Carels VM, Deisseroth K, Bao S (2013) Optogenetic activation of an inhibitory network enhances feedforward functional connectivity in auditory cortex. Neuron 80:10661076. CrossRef Medline

Hattori R, Kuchibhotla KV, Froemke RC, Komiyama T (2017) Functions and dysfunctions of neocortical inhibitory neuron subtypes. Nat Neurosci 20:1199-1208. CrossRef Medline

Houweling AR, Brecht M (2008) Behavioural report of single neuron stimulation in somatosensory cortex. Nature 451:65-68. CrossRef Medline

Houweling AR, Doron G, Voigt BC, Herfst LJ, Brecht M (2010) Nanostimulation: manipulation of single neuron activity by juxtacellular current injection. J Neurophysiol 103:1696-1704. CrossRef Medline

Huber D, Petreanu L, Ghitani N, Ranade S, Hromádka T, Mainen Z, Svoboda K (2008) Sparse optical microstimulation in barrel cortex drives learned behaviour in freely moving mice. Nature 451:61-64. CrossRef Medline

Jazayeri M, Movshon JA (2006) Optimal representation of sensory information by neural populations. Nat Neurosci 9:690-696. CrossRef Medline

Jouhanneau JS, Kremkow J, Dorrn AL, Poulet JF (2015) In vivo monosynaptic excitatory transmission between layer 2 cortical pyramidal neurons. Cell Rep 13:2098-2106. CrossRef Medline

Kapfer C, Glickfeld LL, Atallah BV, Scanziani M (2007) Supralinear increase of recurrent inhibition during sparse activity in the somatosensory cortex. Nat Neurosci 10:743-753. CrossRef Medline

Kerr JN, de Kock CP, Greenberg DS, Bruno RM, Sakmann B, Helmchen F (2007) Spatial organization of neuronal population responses in layer 2/3 of rat barrel cortex. J Neurosci 27:13316-13328. CrossRef Medline

Kim D, Jeong H, Lee J, Ghim JW, Her ES, Lee SH, Jung MW (2016) Distinct roles of parvalbumin- and somatostatin-expressing interneurons in working memory. Neuron 92:902-915. CrossRef Medline

Kim H, Ährlund-Richter S, Wang X, Deisseroth K, Carlén M (2016) Prefrontal parvalbumin neurons in control of attention. Cell 164:208-218. CrossRef Medline

Kohn A, Coen-Cagli R, Kanitscheider I, Pouget A (2016) Correlations and neuronal population information. Annu Rev Neurosci 39:237-256. CrossRef Medline

Kwan AC, Dan Y (2012) Dissection of cortical microcircuits by singleneuron stimulation in vivo. Curr Biol 22:1459-1467. CrossRef Medline

Kwon SE, Yang H, Minamisawa G, O'Connor DH (2016) Sensory and decision-related activity propagate in a cortical feedback loop during touch perception. Nat Neurosci 19:1243-1249. CrossRef Medline

Larkum M (2013) A cellular mechanism for cortical associations: an organizing principle for the cerebral cortex. Trends Neurosci 36:141-151. CrossRef Medline

Larkum ME, Senn W, Lüscher HR (2004) Top-down dendritic input increases the gain of layer 5 pyramidal neurons. Cereb Cortex 14:10591070. CrossRef Medline

Lee SH, Kwan AC, Zhang S, Phoumthipphavong V, Flannery JG, Masmanidis SC, Taniguchi H, Huang ZJ, Zhang F, Boyden ES, Deisseroth K, Dan Y 
(2012) Activation of specific interneurons improves V1 feature selectivity and visual perception. Nature 488:379-383. CrossRef Medline

Lee S, Kruglikov I, Huang ZJ, Fishell G, Rudy B (2013) A disinhibitory circuit mediates motor integration in the somatosensory cortex. Nat Neurosci 16:1662-1670. CrossRef Medline

Lefort S, Tomm C, Floyd Sarria JC, Petersen CC (2009) The excitatory neuronal network of the $\mathrm{C} 2$ barrel column in mouse primary somatosensory cortex. Neuron 61:301-316. CrossRef Medline

Lima SQ, Hromádka T, Znamenskiy P, Zador AM (2009) PINP: a new method of tagging neuronal populations for identification during in vivo electrophysiological recording. PLoS One 4:e6099. CrossRef Medline

Lisman JE (1997) Bursts as a unit of neural information: making unreliable synapses reliable. Trends Neurosci 20:38-43. CrossRef Medline

Manita S, Suzuki T, Homma C, Matsumoto T, Odagawa M, Yamada K, Ota K, Matsubara C, Inutsuka A, Sato M, Ohkura M, Yamanaka A, Yanagawa Y, Nakai J, Hayashi Y, Larkum ME, Murayama M (2015) A top-down cortical circuit for accurate sensory perception. Neuron 86:1304-1316. CrossRef Medline

Markram H, Toledo-Rodriguez M, Wang Y, Gupta A, Silberberg G, Wu C (2004) Interneurons of the neocortical inhibitory system. Nat Rev Neurosci 5:793-807. CrossRef Medline

Miyashita T, Feldman DE (2013) Behavioral detection of passive whisker stimuli requires somatosensory cortex. Cereb Cortex 23:1655-1662. CrossRef Medline

Muñoz W, Tremblay R, Rudy B (2014) Channelrhodopsin-assisted patching: in vivo recording of genetically and morphologically identified neurons throughout the brain. Cell Rep 9:2304-2316. CrossRef Medline

Murphey DK, Maunsell JH (2007) Behavioral detection of electrical microstimulation in different cortical visual areas. Curr Biol 17:862-867. CrossRef Medline

Nichols MJ, Newsome WT (2002) Middle temporal visual area microstimulation influences veridical judgments of motion direction. J Neurosci 22: 9530-9540. Medline

Nienborg H, Cohen MR, Cumming BG (2012) Decision-related activity in sensory neurons: correlations among neurons and with behavior. Annu Rev Neurosci 35:463-483. CrossRef Medline

O'Connor DH, Peron SP, Huber D, Svoboda K (2010) Neural activity in barrel cortex underlying vibrissa-based object localization in mice. Neuron 67:1048-1061. CrossRef Medline

Pala A, Petersen CC (2015) In vivo measurement of cell-type-specific synaptic connectivity and synaptic transmission in layer $2 / 3$ mouse barrel cortex. Neuron 85:68-75. CrossRef Medline

Purushothaman G, Bradley DC (2005) Neural population code for fine perceptual decisions in area MT. Nat Neurosci 8:99-106. CrossRef Medline

Reyes-Puerta V, Kim S, Sun JJ, Imbrosci B, Kilb W, Luhmann HJ (2015) High stimulus-related information in barrel cortex inhibitory interneurons. PLoS Comput Biol 11:e1004121. CrossRef Medline

Romo R, Hernández A, Zainos A, Brody CD, Lemus L (2000) Sensing without touching: psychophysical performance based on cortical microstimulation. Neuron 26:273-278. CrossRef Medline
Romo R, Lemus L, de Lafuente V (2012) Sense, memory, and decisionmaking in the somatosensory cortical network. Curr Opin Neurobiol 22:914-919. CrossRef Medline

Sachidhanandam S, Sreenivasan V, Kyriakatos A, Kremer Y, Petersen CC (2013) Membrane potential correlates of sensory perception in mouse barrel cortex. Nat Neurosci 16:1671-1677. CrossRef Medline

Sachidhanandam S, Sermet BS, Petersen CC (2016) Parvalbumin-expressing GABAergic neurons in mouse barrel cortex contribute to gating a goaldirected sensorimotor transformation. Cell Rep 15:700-706. CrossRef

Salzman CD, Murasugi CM, Britten KH, Newsome WT (1992) Microstimulation in visual area MT: effects on direction discrimination performance. J Neurosci 12:2331-2355. Medline

Schiller J, Schiller Y, Stuart G, Sakmann B (1997) Calcium action potentials restricted to distal apical dendrites of rat neocortical pyramidal neurons. J Physiol 505:605-616. CrossRef Medline

Shadlen MN, Britten KH, Newsome WT, Movshon JA (1996) A computational analysis of the relationship between neuronal and behavioral responses to visual motion. J Neurosci 16:1486-1510. Medline

Shamir M, Sompolinsky H (2004) Nonlinear population codes. Neural computation 16:1105-1136. CrossRef Medline

Silberberg G, Markram H (2007) Disynaptic inhibition between neocortical pyramidal cells mediated by martinotti cells. Neuron 53:735-746. CrossRef Medline

Silver RA (2010) Neuronal arithmetic. Nat Rev Neurosci 11:474-489. CrossRef Medline

Stanley GB (2013) Reading and writing the neural code. Nat Neurosci 16: 259-263. CrossRef Medline

Stüttgen MC, Schwarz C (2008) Psychophysical and neurometric detection performance under stimulus uncertainty. Nat Neurosci 11:1091-1099. CrossRef Medline

Stüttgen MC, Schwarz C (2010) Integration of vibrotactile signals for whisker-related perception in rats is governed by short time constants: comparison of neurometric and psychometric detection performance. J Neurosci 30:2060-2069. CrossRef Medline

Stüttgen MC, Nonkes LJP, Geis HRAP, Tiesinga PH, Houweling AR (2017) Temporally precise control of single-neuron spiking by juxtacellular nanostimulation. J Neurophysiol 117:1363-1378. CrossRef Medline

Takahashi N, Oertner TG, Hegemann P, Larkum ME (2016) Active cortical dendrites modulate perception. Science 354:1587-1590. CrossRef Medline

Wilson NR, Runyan CA, Wang FL, Sur M (2012) Division and subtraction by distinct cortical inhibitory networks in vivo. Nature 488:343-348. CrossRef Medline

Yamashita T, Petersen CCh (2016) Target-specific membrane potential dynamics of neocortical projection neurons during goal-directed behavior. eLife 5:e15798. Medline

Yang H, Kwon SE, Severson KS, O'Connor DH (2016) Origins of choicerelated activity in mouse somatosensory cortex. Nat Neurosci 19:127134. CrossRef Medline 